\title{
The Language Policy Practice in Mathematics Education in the Upper West Region of Ghana
}

\author{
Nabie, M. J. \\ Department of Mathematics Education, University of Education, \\ Winneba, Ghana \\ Ngman-wara, E. I. D. N. \\ Department of Science Education, University of Education \\ Winneba, Ghana
}

\begin{abstract}
Using Teacher's Assessment of Language Policy Practices (TAL2P) questionnaire and unstructured interview schedules, 63 randomly selected teachers (39 females, 24 males) from 21 schools within the Lawra District of the Upper West Region of Ghana were examined to determine the extent to which the language policy was practised. The study showed that teachers teach between $30-46 \%$ of their mathematics lesson periods in English at the lower primary level. Efforts to use the native language for meaningful mathematics instructions are constrained by teachers' inability to speak the language and the lack of materials in the native language. For children to derive the benefits of the language policy, the study recommends taking teachers linguistic competence into consideration during teacher postings and an urgent provision of text materials in the native languages to serve as resource materials for teachers.
\end{abstract}

\section{Introduction}

The issue of language policy for instruction, especially in developing countries, is a common problem that has attracted many researchers and policy makers since language policies have both micro and macro implications (Amoah, 2000; Broch-Utne, 1997 and Bamgbose, 1984). A language policy can either provide or deny access to linguistic capital formation for different groups and individuals or national unity. It is in this respect that formulating and implementing language policies become a major concern among African countries.

Most African countries are multilingual with different language policies. For instance Namibia, according to Broch-Utne (1997), is a country with about 1.5 million inhabitants that has ten (10) Namibian languages as official languages of instruction in the first grades of schooling. This attempt to retain so many African Languages as languages of instruction is seen by linguists as a good initiative that should be appreciated internationally. This is because mother tongue acquisition is an important ingredient in the development of the child's intellect and other aspects of his or her personality. Also, in Zambia education is given entirely in the medium of English language whereas in Tanzania education is given entirely in the mother tongue (Osafehinti, and Nabie, 2001).

As a result of the multilingual nature of African countries many of them have sort to maintain bilingual instructional policies. They adopt a foreign language along side the native language as media of instruction. This is because instruction in the mother tongue is basic for people's existence and 
identity and a decisive factor in the process of integrating and consolidating national unity.

The instructional value of a native language in African countries cannot be over stressed. Evaluation of studies that compare the native language and English language as medium of instruction for concept acquisition among children in Ghana (Collison, 1974), in Nigeria (Bamgbose, 1984; Adetula, 1990), and in Namibia (Brock-Utne, 1997) consistently showed that where English was used, majority of the children were not able to exercise their conceptual potential. In these studies, the performance of children was superior when problems were given in the mother tongue than in English. This shows the superiority of starting off instructions with the mother tongue, since "the local vernacular is a much more effective medium of instruction in the first two primary grades than English" ( Bamgbose (1984: 95). This suggests that more use of the first language and less use of the second language seems to give better results. However, bilingual upbringing on pupils attainment in some countries have provided progress in certain schoolwork especially problem solving (McNamara 1967), Sharfuddin, 1984) cited in Osafehinti and Nabie (2001). Review studies show that, bilingual children may well be in advantageous position as compared to monolingual children (Austin and Howson, 1979). Bilingual education caters for children linguistic experiences and is often seen as a means of improving the educational attainment of indigenous children especially in developing countries. However, the general consensus based on research findings and experience is that the child suffers some kind of retardation as a result of partial linguistic mastery (Auerbach, 1993). Hence the need to ensure full mastery of the medium of instruction by pupils at the primary school if the language policy is to be beneficial to them.

It had earlier been observed that when a learner's linguistic experience are not catered for in the classroom, the learner finds himself at a crossroad not knowing what to do (Clarkson, 1991) cited in (Osafehinti and Nabie, 2001). A similar confusion was observed in a recent study in Ghana conducted by the Performance, Monitoring, and Evaluation (PME) Unit of the USAID in the Upper East Region on the achievement of primary 3 and 5 pupils in Mathematics and English. The study showed that when test items were read in English pupils could not write anything but when the items were read in the native language pupils were found busy working and writing down answers (Amoah, 2000). This further supports earlier findings' that children feel more comfortable learning in their own language.

Auerbach (1993) argues that, whiles there is no evidence that the exclusive use of English results in greater or more complete acquisition of knowledge, there is still significant evidence against its exclusive use in the classroom. Auerbach (1995) points out that, the exclusive use of English in the classroom results in non-participation, frustration and eventual dropout, and pupils' inability to build on existing native language literacy skills. The use of native language in teaching therefore serves as a natural bridge for pupils to overcome their learning problems and helps them to make rapid gains in the English language development. 
While policy makers recognize the need to promote all mother tongues, there are several problems that militate against their implementation. Bamgbose (1976) points out that these language policies are not stated explicitly. The policies are often vaguely indicated with no rigid rules or laws as to which language or recommended texts to use. He contented that there is often inconsistency between policy and practice. So teachers tend to use any language freely in schools, especially in the rural areas. Besides, the educated elite who usually praises the virtues of education in the mother tongue often prefers local private schools or foreign countries where English and French are taught right from primary one that frequently abuses the policy. Consequently, the mother tongue or state language is not a popular choice among the students or the instructors even when made available.

Mathematics is an indispensable tool in the formation of an individual. It broadens and sharpens ones intellectual capabilities, and helps the individual to understand, interpret and to give accurate account of the physical phenomena observed in the environment. In this regard, it is important that mathematics is taught at all levels through the appropriate medium for better understanding. Children must be instructed in a language that they understand to enable them benefit from the subjects on which their future development rests. To lay a firm and consolidated foundation in mathematics, therefore, means using the appropriate medium of instruction for mathematics education. It is for this reason that in Ghana several attempts were made by the Christian Missionaries and ruling Government to enhance the development and use of indigenous languages for instruction. They all believe that instructional objectives can only be realised if learners are instructed in a language they can speak and understand very well (Andoh-Kumi, 1997). It is argued that when children are not instructed in the mother tongue at the lower primary, the school is depriving a part of the population from learning (Lind, 1995, cited in BrockUtine, 1997)

Being aware of the role language plays in the intellectual development of the child, and the eminent consequences of using a particular Ghanaian Language as the official medium of instruction, Ghana has maintained a flexible bilingual policy for instruction. The official language policy stipulates that a Ghanaian language be used during the first three years of primary school education as the medium of instruction for all subjects whiles English remains a subject to be studied. After the first three years English becomes the medium of instruction and the Ghanaian languages then become subjects of study (Ghana Education Service - GES, 1988; ERRC. 1995). For teachers to be able to cope with the language policy of instruction at the lower primary level, initial teacher trainees are expected to study one other Ghanaian language other than their own (ERRC, 1995). The Teacher Education Unit (TEU) of the GES is therefore required to take teachers linguistic backgrounds into consideration during teacher postings to basic schools. However, there are many teachers in communities where the native languages spoken are 'foreign' to them and they can neither understand nor use the language for classroom instructions. Taking the nature of teacher postings into consideration, the study is therefore 
designed to examine the extent to which the language policy, as it stands, is being practised at the lower primary level.

\section{Research Questions}

The study seeks to address the following questions:

(i) Are basic school teachers aware of the national language policy for instruction at the level they teach and what is their perception of the language policy?

(ii) What proportion of teachers is able to communicate in the native language during mathematics instruction?

(iii) What proportion of each instruction activity in mathematics reflects the use of the native language?

(iv) What problems militate against the implementation of the language policy for mathematics instruction?

\section{Significance and scope of the study}

Currently, there is agitation from various pressure groups in Ghana for a review of the language policy. The study on the language policy designed to determine the extent to which teachers are implementing the policy of instruction at the lower primary level could provide statistical data for the government on how the language policy is practised. The statistical evidence will could provide basis for the central government to rethink the universality of national language policy practice and a possible review or otherwise. In addition, child educators will become aware of the importance of language in classroom instruction and therefore plan to meet the linguistic needs of a heterogeneous classroom.

Although the problem of language policy for classroom instruction is a national issue, it is not possible for the study to cover the whole nation in view of the cost and the bulk of data that will be involved for a national study. Consequently, the study was restricted to teachers within the Lawra District of the Upper West Region of Ghana because it is one of the most deprived districts in the region that does not attract professional teachers.

\section{Research Methodology}

\section{Population}

The study covers lower primary school teachers within the Lawra district of the Upper West Region in Ghana. The district is located in the northwestern part of the region. Natives of this locality are predominantly subsistent farmers who speak Dagaare.

\section{Sample}

A random sample of 21 schools selected from the 52 primary schools within the district was used for the study. Names of the 52 schools were written on pieces of paper, which were folded and put in a box. The schools were picked at random from the box one at a time (with replacement) until the 21 schools were selected. This method was used to ensure that each school had an equal chance of being selected. 
All the lower primary school teachers (that is, primary one to three teachers) in the selected schools were considered for the study. In all, 63 teachers out of 156 lower primary teachers in all the 52 primary schools within the district were involved in the study. The sample was made up of 39 female and 24 male teachers comprising 42 professional and 21 non-professionals.

\section{Instrumentation}

Two instruments, namely the modified form of Osafehinti and Nabie's (2001) Teacher's Assessment of Language Policy Practices (TAL2P) and unstructured interview schedules were used for the study. The TAL2P is a questionnaire made up of 3 sections (A, B, and C). Sections B and C of the TAL2P were modified to suit this study. This instrument, TAL2P, had exhibited an alpha coefficient of 0.91. Teachers were assured that their responses would be treated with utmost confidentiality and so they were open in their responses.

Section A of the instrument had 8 items designed to collect background information about the teachers. It also sought to find out the language of the locality, the native language of the teachers and the language that the teachers often use for classroom instructions. In addition, part of this section focused on the teacher's designation as to whether he/she is a head teacher, a class or subject teacher and the gender.

Section B was designed to estimate the proportion of the lesson period in teaching mathematics for which either the native language or English is used in the teaching process. In the (TAL2P), teachers were expected to shade any number out of the five squares arranged between native language and English language to reflect the proportion of lesson period in which either of the two languages was used. Each box represented $20 \%$ of the time of the lesson period. The modified TAL2P divided the squares in such a way that $5 \%$ of the lesson period for which either language is used could be indicated. For example a response in respect to the introduction of a lesson representing $65 \%$ use of native language may take the following pattern:

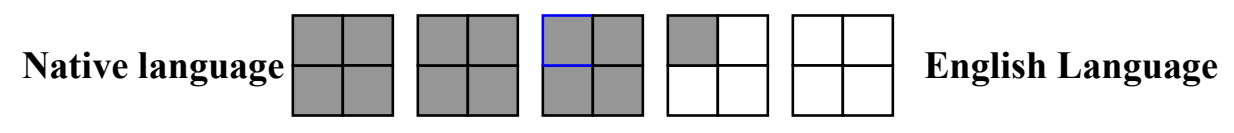

The last section, $\mathrm{C}$, had ten items. The items were designed to find out whether the teacher studied Ghanaian Language at the training college, find out the problems teachers face in the use of the native language for mathematics instruction. In addition, they sought to find out how effective teachers are in the use of the local language, and whether there are available textbooks in the native language as guides. Teachers' views about the language Policy and their suggestions/impressions about the present state of the language policy were also sought.

The questionnaires were administered to teachers at their various schools. The teachers were given enough time to respond to them. The teachers were not allowed to take the questionnaire home to avoid others from influencing them, if they were allowed to do so. 
Based on the responses, interviews were held with individual teachers to further elicit their expressed views. The pattern of the interview was determined by the nature of the responses provided. An enabling atmosphere was created for teachers to open up.

\section{Analysis}

Frequency counts on the number of teachers who are natives and had training in the use of the native language for instruction were determined. These were converted into percentages. Also, from the responses the proportion of lesson period in which the native language is used as medium of interaction in various aspects in teaching mathematics was computed.

\section{Results}

The instrument for the study on the language policy practice of basic school teachers, in general, sort information on teachers' linguistic background, what language they often use for classroom mathematics instruction, and their views about the language policy as it stands. The results of teachers' responses are presented in tables and figures.

Figure 1 shows the native languages of teachers who teach at the lower primary level in the schools under study.

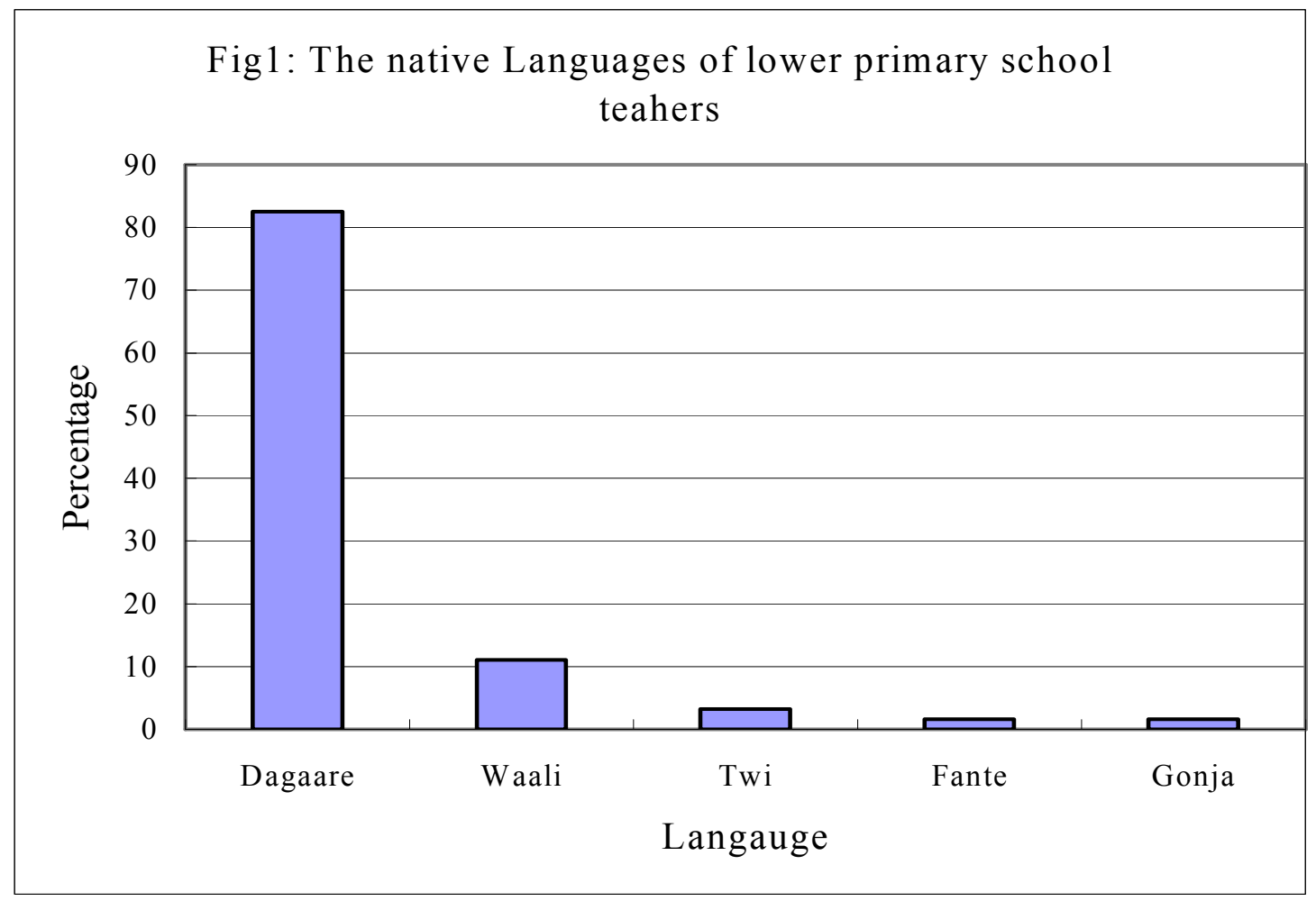

Figure 1 shows that $82.5 \%$ of the lower primary school teachers are speakers of the native language of the locality, Dagaare. Also, 11.1\% of the teachers speak Waale, which is closely related to the native language of the locality. Evidently $6.4 \%$ of the teachers were non-speakers of the native language. The high percentage of teachers who are non-natives suggests 
that most teachers can effectively communicate with the common language of instruction, Dagaare, the language spoken by the inhabitants of the school community. The non-native language speakers were interviewed. Asked why they opted to teach at the lower level when they could not communicate in the children's language, many of them claimed that the situation was above them. "There was nothing I could do since the upper primary was equally occupied" one responded. One newly trained teacher responded, "I was just posted there so I felt that was where my services were most needed". The female teachers among them however, responded that they had to join their husbands who were working in departments within the district.

Teachers' responses on the language they often use for mathematics instruction is as shown in Fig 2.

Fig 2 Teachers responses on their medium of instruction

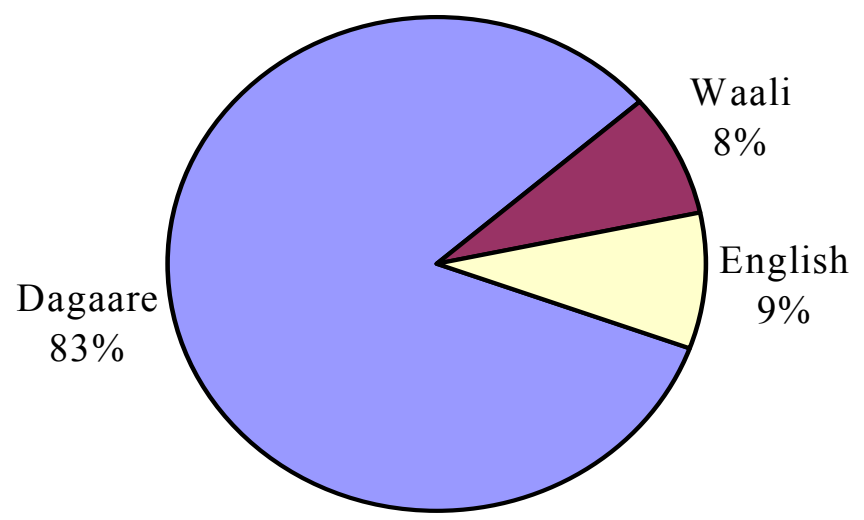

Fig. 2 shows that $83 \%$ of the teachers frequently used Dagaare, $8 \%$ used Waali and 9\% used English for mathematics instruction. The high percentage of teachers in the area where they can communicate in the native language of the pupils is an indication of the implementation of the language policy for instruction.

Table 1 shows the mean percentage responses of teachers on certain aspects of policy implementation that can influence the language policy practice. Table 1 shows that a high proportion of teachers are aware of the language policy, $(80.3 \%)$. Those who have control over the use of the native language for instruction constitute $72.9 \%$. Also $64.4 \%$ of the teachers had studied the language during training. Unfortunately, many teachers $(98.3 \%)$ indicated they have no guides to support them on the use of the language for instruction. 
Table 1 Mean percentage responses of teachers on aspects and perception of the language policy practice

\begin{tabular}{lc}
\hline Variable & $\begin{array}{c}\text { Percentage making } \\
\text { Yes responses }\end{array}$ \\
\hline Aspects of policy & \\
Awareness of the language policy for instruction & 80.3 \\
Teachers who study a Ghanaian language in college & 64.4 \\
Teachers with control over the use of the native language & 72.9 \\
Availability of Ghanaian Language guides for instruction & 1.7 \\
Teachers who face problems using the language & 44.8 \\
Perceptions & \\
The language policy is successful & 76.8 \\
The language policy needs modifications & 55.4 \\
\hline
\end{tabular}

The non-existence of textbooks and teacher's guides in the native language can make it difficult for teachers to find appropriate vocabulary in describing mathematical concepts. This probably explained why most teachers faced problems using the native language in teaching (55.2\%). The majority of teachers (76\%) see the language policy as successful while $55 \%$ of teachers are of the view that the policy be modified to ease some of the problems they faced.

The means of the proportions of aspects of instruction for which the native language was used for mathematic teaching process are shown in Table 2

Table 2 Means of proportions of aspects of instruction for which the native language is used

\begin{tabular}{lcc}
\hline \multicolumn{1}{c}{ Aspects of Instruction } & $\begin{array}{c}\text { Percentage using } \\
\text { Native Language }\end{array}$ & $\begin{array}{c}\text { Percentage using } \\
\text { English Language }\end{array}$ \\
\hline Introduction of Lesson & 61 & 39 \\
Explaining a Point & 62 & 38 \\
Demonstration & 61 & 39 \\
Giving Instruction & 60 & 40 \\
Giving Exercise/Homework & 59 & 41 \\
Guiding Pupils in doing Exercises & 54 & 46 \\
Asking questions & 58 & 42 \\
Verbal Motivations & 55 & 45 \\
Guidance and Counseling & 70 & 30 \\
\hline \multicolumn{2}{c}{$\left(\chi^{2}=26.552 ; \mathrm{p}<0.01\right)$} &
\end{tabular}

Table 2 shows that, in general, lower primary school teachers use both the native language and English for mathematics instruction. However, a chisquare analysis showed significant usage of the native language for 
mathematics instruction compared to English language $(\chi 2=26.552 ; \mathrm{p}<$ 0.01).

Teachers use more than $53 \%$ of the native language but less than $71 \%$ in all aspects of the mathematics teaching process. The native language is used highest during guidance and counseling (70\%) and least used when teachers are guiding pupils on their exercises (54\%). The high use of the native language in Guidance and Counseling is probably because Guidance and Counseling services do not require the use of technical terms. Teachers' responses showed that the native language is equally used during the introduction of a lesson and demonstrations. They both show $61 \%$ use of the native language. In all the other aspects of lesson presentation, the use of the native language for instruction is still higher than the use of English language. Despite the higher proportion of the use of the native language in various aspects of instruction, teachers use an appreciable proportion of English in the various aspects of mathematics instruction. This situation is an indication of problems with the implementation of the language policy at the lower primary level.

\section{Discussion and Conclusion}

A language policy is operational when measures are put in place to ensure that it is practised. The results in figure 1 shows that many lower primary school teachers are speakers of the native language of the locality, Dagaare. This suggests that to some extent, efforts are made to ensure that language barrier that can have negative effect in classroom learning is eliminated or reduced. Mathematics instruction requires a unique form of communication. Children can become truly proficient in mathematics if they are able to understand and relate the mathematical ideas communicated to them.

The results show that a greater percentage of teachers often use the native language of the locality, Dagare, (83\%) and $8 \%$ of the teachers use a closely related language, Waali, for mathematics instruction. This means that $91 \%$ of the teachers often use a native language that is quite understandable by both the teacher and pupils (see fig 2). This suggests that teachers are aware that the native language is a more efficient means of instruction (Bamgbose, 1984) and an important tool for the intellectual and personality development of the child (Legere, 1995). The fact that there is no communication barrier between pupils and teachers can be a source of motivation that will encourage children's participation in the learning process. However, 9\% of lower primary school teachers who could neither speak the native language of the locality, Dagaare, nor the closely related language, Waali, use English language for mathematics instruction.

This exclusive use of English can result in non-participation, frustration (Auerback, 1995) and might probably be one of the reasons why some children tend to make choices against mathematics. This further suggests that children instructed exclusively in English language will often find themselves at crossroads not knowing what to do (Clarkson, 1991; Amoah, 2000). Children find themselves in such classroom situations because there are no rigid rules to enforce the policy (Bamgbose, 1976) and are merely learning by rote since the language barrier will be a hindrance for classroom 
discussions through which mathematical ideas are shared, evaluated and amended (Nabie, 1997).

Responses given by non-native language speakers also suggest teacher postings, to some extent, do not take into consideration the linguistic competencies in the native languages. Rather, teacher postings are constrained by need and labour mobility.

Teachers' responses on statements that influence the implementation of the language policy for instruction, in general, suggest problems with the implementation process. Though about $64 \%$ percent of the teachers had studied Ghanaian language during training and about $77 \%$ of the teachers regard the current language policy as useful, about 55\% recommended a modification of the policy and about $45 \%$ of those who use the native language have problems. Also, about $36 \%$ of the teachers, comprising some professional and non-professionals did not study Ghanaian language at all and some of those who studied Ghanaian language perhaps did so in other languages other than Dagaare or Waali. These teachers obviously will not be conversant with the dynamics of the language of the locality. A high proportion of the teachers $(72.9 \%)$ have control over the use of the native language for mathematics instruction (see Table 1). However, they did not show exclusive use of the native language for instruction. Teachers instead used both the native language of the locality and English for mathematics instruction. Even though teachers often use the native language for mathematics instruction in all aspects of the instructional process (Table 2), the proportion of lesson period for which the native language is used is relatively lower than expected. This might be due to teachers' inability to obtain the native equivalent of mathematical terms. Both non-professionals and the professionals were substantially using English for instruction.

For the non-professional teachers, their situation would be quite understandable since they have no training on the use of native languages for classroom instruction. On the other hand, the inability of the professionals, especially those who can speak the native language of the locality, to exclusively use the native language suggests either poor preparation of teachers or it is not easy using the native language for mathematics instruction. The non-existence of text materials or guides for teachers to use for mathematics instruction (Table 1) means that teachers are likely to use their own terms which may have different meanings from the concept. The poor training of teachers on the use of native languages, problem of native equivalence of mathematical terms, and the total absence of materials can greatly impede the implementation of the language policy for mathematics instruction.

In general, the lesson period for which the native language is used for all aspects of mathematics instruction ranged from 54\% in guiding pupils to do their exercises to $70 \%$ in providing pupils with guidance and counseling services. This means that teachers teach between $30 \%$ and $46 \%$ of lesson period in English at the lower primary level. Giving explanations, asking questions, and giving instructions, which one would expect, a higher use of the native language was less than expected. They recorded $62 \%, 58 \%$, and $60 \%$ respectively. Children's understanding in aspects of mathematics 
instruction would be limited as a result of limited usage of the native language. The unexpectedly high usage of English can be attributed to:

- the poor training of teachers on the use of native language for mathematics instruction

- the unprofessional status of some of the teachers

- the problem of language equivalence

- lack of materials

- $\quad$ some teachers who did not study the language of the locality, and

- disregard of teachers' linguistic competencies in native languages during teacher postings.

Teachers seem to be aware of the significance of the language policy on the mathematical development of children and try to practise it. They make effort to use the native language of the locality or a related language that children can understand for all aspects of mathematics instruction process. However, their efforts to use the native language for instruction are constrained by lack of materials in the native language to guide them. Some teachers are still posted to communities where they can neither speak the native languages nor understand them either because they had to join their working partners or out of need. In this circumstance, they are compelled to resort to the official national language. Children in their classrooms are most likely to find it difficult to understand the mathematical concepts. In addition, both trained and untrained teachers who even though could speak the language lacked the vocabulary and skills of using the native language as a medium for classroom mathematics instruction. Many lower primary school teachers therefore mostly combine both the native language and English for instructions because they lack the dynamics of using the native languages. The language policy for instruction therefore is not fully implemented for lack of direction from the policy makers. Appropriate mathematical register in a native language can have serious implications for mathematics instruction in the native language and would be an interesting area for further research.

\section{Suggestions}

The language a child speaks significantly contributes to his or her progress in mathematics education. To enable children derive the full benefits of the language policy for instruction at the lower primary school level, the following are recommended:

- posting of teachers to lower primary should take cognizance of the their linguistic ability;

- government should make conscientious effort to provide textbooks and guides on the natives languages with the appropriate mathematical register in these languages to serve as resource material for teachers;

- periodic training of teachers at the district level on the use of the native languages for mathematics instruction should be instituted and maintained;

- there should be vigorous supervision to enforce the implementation of the policy; and 
- contraction of the Languages Departments in the Universities and Institutes to develop instructional materials in the native languages for use at lower primary.

\section{References}

Adetula, L. O. (1990). Language Factor: Does it Affect Children's Performance on Word Problems? Educational Studies in Mathematics Vol. 21.

Amoah, C. (2000). Report of National Workshop on Improvement of Collection and Processing of Statistics Related to Youth and Adult Literacy in Ghana.

Andoh-Kumi, K. (1997). Language Education Policy in Ghana. London: Longman, Green \& Co.

Auerbach, E. R. (1995). The Politics of the ESL Classroom: Issues of Power in Pedagogical Choices. In J. W. Tollefson Power and Inequality in Language Education. Cambridge: Cambridge Univ. Press, 9-33

Auerbach, E. R. (1993). Re-examining English only in the ESL Classroom. Tesol Quarterly. Educational Researcher. 25 (5).

Austin J. L. and Howson, A. G. (1979). Language and Mathematics Education. Educational Studies in Mathematics. 1 (2), 161-197

Bamgbose, A. (1976) (ed.). Introduction: The Changing Role of the Mother Tongue in Education. In Mother Tongue Education. The West African Experience. London: Hodder and Stoughton, 9-26

Bamgbose, A. (1984). Enseignement en langue Matenelle et reussite scolaite au Nigeria, Perspectives. Vol. XIV No 1, 89-96

Brock-Utne, B. (1997). The language question in Namibian schools. International Review of Education, 43 (2/3), 241-260.

Collison, G. O. (1974). Concept formation in a second language: A study of Ghanaian School Children. Harvard Educational Review 44 (3), 441 457

ERRC (1995). Report of the Education Reform Review Committee. MOE, Ghana.

G. E. S. (1988) Mathematics Syllabus for Primary Schools. CRDD, Accra.

Legere, K. (1995). Language in Namibian Education Achievements and Problems. Paper presented at the National Workshop on African Languages in Basic Education held at NIED in Okahandja from 18-22 September, 1995

Nabie, J. M. (1997). Children and Mathematical Investigations. Ghana Educational Media and Technology Association Journal, 1 (1), 17-26

Osafehinti, I. O. and Nabie M. J. (2001) A study of Language Policy Practice at Upper Primary School Level in Ghana. Journal of Ghanaian Language Education. Vol. 1, 10-23 